\title{
FETICHES VISUAIS EM TEMPOS DE CONVERGÊNCIAS TECNOLÓGICA, MERCADOLÓGICA, CULTURAL E SOCIAL
}

\author{
Visual Fetishes in Times of Technological, Markething, Cultural and Social \\ Convergences
}

\section{RESUMO}

Neste artigo, faz-se uma breve exposição dos conceitos de fetiches visuais em tempos de convergências tecnológica, mercadológica, cultural e social, estilos e discursos enquanto fenômenos de expressão. Ao final, apontam-se algumas questões sobre a relação entre esses conceitos e a ideologia do cotidiano em Bakhtin.

Palavras-chave: fetiches visuais, convergências, fenômenos de expressão

\section{ABSTRACT}

This article comprises a brief exposition of the concepts for visual fetishes in times of technological, marketing, cultural and social convergences, styles and speeches while seen as phenomena of expression. At the end, a few issues are pointed out regarding the relation between these concepts and Bakhtin's ideology on everyday life.

Keywords: visual fetishes, convergences, expression phenomena. 


\section{INTRODUÇÃO}

Quando pensamos nas redes sociais e o quanto se impõem em nossos tempos de convergência tecnológica, mercadológica, cultural e social, revitalizamos os Software educacionais, tais como os que usavam a linguagem LOGO, no final da década de 1990, a própria internet, que adentraram também o espaço escolar que se encontrava ansioso por novos caminhos de criação, por novos fenômenos de sentidos educativos: "na esfera da cultura, todavia, não há fronteira absoluta entre a carne e o sentido: a cultura não se edifica a partir de elementos mortos, e o vulgar tijolo, como já disse, entre as mãos do construtor, expressa algo através da forma que lhe é própria" (Bakhtin, 2000, p. 367).

Para o autor, "fenômenos de sentido" (p.365) são elementos que, mesmo ocultos aos olhos, estão presentes nas formas de pensamento, por exemplo, os "tijolos" que, mesmo conservando sua forma, deixam-se moldar expressando sentidos: "Os fenômenos do sentido podem existir em forma latente, potencial, e revelar-se somente num contexto de sentido que lhes favoreça a descoberta, na cultura das épocas posteriores" (Bakhtin, 2000 ,p.365). Na educação e num contexto cultural mais abrangente, podemos olhar para o que vivemos como composição de um tempo duradouro de construções criativas moldadas desde a década de 80 , mais expressivamente, e que nos apontam para um desejo cidadão de conhecimento e participação crítica:

As concepções pedagógicas críticas operaram como contraponto às idéias sistematizadas na teoria do capital humano que, formuladas nos anos 50 e 60, se impuseram a partir dos anos 70, mantendo sua hegemonia mesmo nos anos 80 , quando o forte desenvolvimento das teorias críticas suscitou a expectativa de sua superação. Tal conclusão fica evidente à luz dos acontecimentos da década de 90 , quando se manifesta com toda força a idéia da educação como instrumento mais poderoso de crescimento econômico e, por consequência, de regeneração pessoal e de justiça social (Saviani, 2008, p.115).

Um novo olhar sobre a ideologia, o conhecimento e a verdade emanada dessa relação que começava a existir entre a informática educativa e a imagem, produzia novos sentidos na cultura educadora e outros interlocutores sociais. Santaella e Nöth, estudiosos da semiótica - em síntese, semiótica pode ser definida como a ciência que estuda as condições gerais dos signos como signos e em relação ao pensamento (Santaella e Nöth, 1998, p.39) - encontraram em Peirce a base para entender o que eles definiram 
como paradigma pós-fotográfico, em contraponto ao já apresentado. Nesse paradigma, o processo de produção é eminentemente mediado por linguagens especificas para computador, por exemplo, a infográfica - proporcionada pelos pixels - garantindo uma imagem em perpétua metamorfose (Santaella e Nöth, 1998, p.166). Ao produzir imagens sintéticas e icônicas, pode-se proporcionar alternativos e polissêmicos significados, pois “... não há nada na definição peirciana da representação que restrinja seu objeto dentro dos limites de um referente externo perceptível" (Santaella e Nöth, 1998, p.166).

Imagens polissêmicas e polifônicas, fora de uma representação externa perceptível do objeto (Santaella e Nöth, 1998, p.160), apresentam-se em uma multiplicidade de vozes, assumindo vários papéis discursivos ao longo da leitura das imagens pelo sujeito (p.116). O que parecia ter como consumo passivo e conteúdo definido, inclusive em relação às imagens na Arte, hoje se aceita substituir, variadas vezes, pelo poder de contemplação de um artista que pode ver o que tem diante de seus olhos sem, necessariamente, ter que substituir o que vê por nenhuma interpretação de juízo definitivo (p.216-217): ou seja, pode até ver com todos seus "olhos" e "sujeitos", como que estetizando aquilo que vê (Canevacci, 2008, p.92).

O que rompia com o ensino behaviorista em informática educativa que se apresentava naquela época, também propunha um re-olhar sobre a visão "congelada" de uma imagem, fato e documento, e, consequentemente, com a própria discussão do que se entendia por produção de realidade, verdade e conhecimento em linguagens midiáticas (som, imagem, narrativas e gêneros ficcionais, ...). A emergência de uma cultura visual e midiática, a partir dos anos 1970, no Brasil, ofereceu suporte para leituras em outras linguagens e passou a contribuir com

um outro modelo de aquisição e apropriação de conhecimentos, bem como estimulando a difusão generalizada do imaginário de uma ficção midiática, apresenta[ndo] uma nova organização de ideias e representações sobre o mundo (Setton, 2004, p.68).

Setton complementa a ideia, afirmando que, sobretudo as gerações mais jovens foram se socializando nessa " [..] cultura da imagem, do texto fragmentado, da montagem e bricolagem - "atividade imaginativa, mitopoética, contrapondo-se ao trabalho ordenado, metódico e predeterminado" (Pizzi; Fumes, 2007, p. 308) —incessante de informações" (p.68). Bricolagem de uma ação docente que também compôs, nessas três últimas décadas do século $\mathrm{XX}$, seus próprios processos associativos de pensamentos behavioristas e construtivistas que, em fluxo nessa relação, reverberaram especialmente junto às leituras que se fazia das linguagens midiáticas. Assim, é possível afirmar que hoje se está inserido 
milhões de pessoas e interferem em suas opiniões e em sua forma de aprender, de ver e de pensar (Duarte et al.In: Setton, 2004, p.37).

Sob a ótica de Sabat (In: Setton, 2004), a imagem, hoje, é uma das características do mundo e da cultura contemporânea, sendo "inevitável sua transformação em objeto de estudo e pesquisa acadêmicos" (p.132). Ao analisar as personagens de desenhos e filmes infantis de animação, a autora acredita que a sua proliferação e a dos produtos comercializados apresenta não somente um vocabulário próprio, mas interfere nas brincadeiras, nos modos de ser e nos velhos e novos saberes que, unidos ao currículo escolar, se apresentam como currículo cultural que "prima por não ensinar conhecimentos científicos, mas modos de conduta, de comportamentos, hábitos, valores e atitudes, produzindo, assim, identidades culturais".

Segundo Sabat (In: Setton, 2004), o currículo cultural funciona mediante uma lógica que parece não reconhecer fronteiras entre conhecimento escolar e conhecimento cotidiano (p.132) ao prescrever esses modos de conduta, "através de artefatos que vão desde o cinema, televisão, publicidade, histórias em quadrinhos até outdoors, moda, música, revistas" que estão, em grande parte, na mídia. E complementa:

Criar condições para que discussões deste tipo façam parte do cotidiano escolar significa, portanto, aumentar nossas possibilidades de educar sujeitos para uma sociedade na qual a diferença seja vista com respeito e não como um problema a ser resolvido' (Sabat, In: Setton, 2004, p.135).

Neste contexto para além-escolar, a atividade estética e ética que emerge desse cotidiano cultural em que se encontra hoje o jovem, ele parece se concentrar no que pode ser considerado disperso, atraindo imagens e expressões em que o efêmero também tem um novo significado (Bakhtin, 2000, p.205). Ele não só é o destinatário desse currículo cultural, ou digital, mas também é o remetente. Hoje, ele é conectado socialmente, é barulhento e público. Se expressa em filmes pornôs-soft - feitos em questão de minutos e, em segundos, publicizados - com aparelhos de mídias pessoais, podendo serem vistos por quem os queira (Jenkins, 2008, p.43), em uma cultura que, cada dia mais, converge para um novo perfil de consumidor, o qual, agora também parece assumir o controle convergente para ideias em relação aos seus próprios fetiches nestes tempos em que os fenômenos de sentidos se transformam em imagens e linguagens digitais, compartilhadas infograficamente. Sujeito a metamorfoses, essas linguagem se travestem em polissemicos significados e fetiches.

Fetiche e fétichisme, em francês, e feitiço em português, está relacionado a sortilégio, pois, ao anunciar o poder sobrenatural e mágico de um amuleto, por exemplo, destaca-se pela relação com os fenômenos religiosos dali emanados. Segundo Duarte (2004, p. 01), fetichismo é um fenômeno de origem religiosa por envolver o culto de alguma entidade, de algum deus. Para o autor, seu entendimento parte da época bíblica, mais especificamente do Antigo Testamento, no livro Éxodo, no qual se lê que era preciso garantir a destruição "(...) [das condições de reprodução material dos povos inimigos", 
seja de seus altares ou de suas estátuas que representavam a unidade simbólica do povo inimigo (p.03).

O conceito de fetiche tem despendido um olhar atento de pesquisadores sociais ao longo do tempo, por exemplo, os desenvolvidos em relação à sexualidade, por Sigmund Freud, e à mercadoria (enquanto produto econômico de determinada sociedade), por Karl Marx. Revolucionário alemão nascido no século XVII e fundador da doutrina comunista moderna, MarX apresentou a essência alienante da sociedade capitalista ao decompor a mercadoria em valor de uso e valor de troca:

\begin{abstract}
Segundo Marx, o caráter de fetiche da mercadoria advém do fato de seu caráter de coisa esconder as relações sociais, de exploração do trabalho alheio pelo capital que de fato a produzem. Daí a mercadoria se tornar algo misterioso, místico e "metafísico": um objeto inanimado que parece ter vida própria, fora de controle tanto daqueles que 0 produzem quanto daqueles que o consomem (Duarte, 2003, p.32).
\end{abstract}

A mercadoria, enquanto fenômeno produzido nas relações sociais, esconde o fetiche enquanto produto econômico. O valor pela troca não é nada mais do que um valor instituído socialmente a fim de dar "concretude" a algo que existe em devir. Também em Freud, psicanalista austríaco, nascido em 1856, o conceito de fetiche infere uma "coisa" que apesar de parecer não estar explícita, existe, e, na trama da relação, busca substituir algo que falta, uma aparente ausência ou desejo.

O princípio geral do objeto fetiche, em todas as suas formas, concerne o fato de que ele sempre encarna algo com o qual tem uma relação atribuível, mas que sempre o oculta, substituindo-o: no caso do fetiche da mercadoria são as relações sociais de produção da própria mercadoria que são encobertas; no caso do fetiche sexual é o desejo sexual ou o "objetivo sexual normal"; no caso do "fetiche dos primitivos", eram os deuses; e no caso do fetiche do objeto de consumo estão encobertas, além das relações sociais de produção, a própria subjetividade alienada do sujeito e seu desejo de completude narcísica (Cruz, 2007, p. 56).

Ao se discutir o conceito de fetiche, sob a perspectiva do convite formulado por Canevacci que o relaciona ao visual, definindo-o como fetichismos visuais (no plural), pode-se pensar que esse sujeito, hoje espectador/ consumidor/ leitor jovem e escolarizado, reificado entre coisa e pessoa, parece não só incorporar esses que seriam os fetichismos visuais em sua materialidade enunciativa, mas imergir na busca de "completude" de sentidos. Parece tentar tacitamente substituir "sociedade e fábrica" (ou seria escola e re-produção?) por "comunicação e metrópole" (Canevacci, 2008, p.19), semelhante à saga bíblica descrita no Éxodos. Deduz-se que a escola precisa aceitar estátuas e altares enquanto unidade simbólica que vivifica as enunciações desses sujeitos contemporâneos, fazendo da "coexistência entre" no lugar da "substituição por" um lugar possível nas ações pedagógicas.

Segundo Pardo (2010, p.115), há pelo menos três razões docentes que contribuem para dificultar a ação pedagógica nesses novos tempos da informática educativa contemporânea: 
a) el desprecio de los contenidos audiovisuales como forma de conocimiento formal dentro de la dieta cognitiva;

b) la pobre integración de las prácticas mediáticas de los jóvenes en el aula

c) y la desmitificación del rol del libro como vehículo central del aprendizaje.

A relação pedagógica que emerge nesses tempos de convergência tecnológica, mercadológica, cultural e social com mercadorias sem fronteiras estabelecidas não somente entre produto e produtor, entre sociedade e metrópole (... e seus fetiches), mas especialmente entre professores e alunos parece ser um convite insistente aos educadores para pensar sobre o que se define como "dificuldades" pedagógicas e fazer docente nestes tempos de tentativas convergentes a que todos estamos imersos. Prensky (2009), em 2001 conceituou "nativos digitais" e "imigrantes digitais" na tentativa de discutir as diferenças entre os jovens de nossos dias e seus predecessores, incluindo nesse grupo os professores, e hoje discute a limitação desse conceito:

\begin{abstract}
Although many have found the terms useful, as we move further into the $21^{\text {st }}$ century when all will have grown up in the era of digital technology, the distinction between digital natives and digital immigrants will become less relevant. Clearly, as we work to create and improve the future, we need to imagine a new set of distinctions. I suggest we think in terms of digital wisdom (Prensky, 2009, p.1).
\end{abstract}

Portanto, "sabedoria digital" parece ser um termo mais apropriado a esse tempo do qual falamos, em que a capacidade de produção de sentidos está alterada, do mesmo modo que os olhares sobre a ideologia, 0 conhecimento e a própria educação. Concordando-se com o autor, não interessa de que forma se denomine esse novo humano emergente, se Homo Sapiens digital, digital ou humano; o importante é reconhecer que essa revolução inclui tanto o digital quanto o sábio cuja meta maior será a de desenvolver a sabedoria nessa própria relação, que se acredita, terá na ética e na estética bakhtiniana o seu principal viés dialógico, de modo que garanta espaço para emergência de processos criativos do conhecimento, não apenas de natureza científica, mas especial e fundamentalmente filosófica, estética e ética, conforme afirma Axt (2000, p.59).

\title{
REFERÊNCIAS
}

AXT, M. Tecnologia na Educação, Tecnologia para a Educação: um texto em Construção. Informática na Educação: teoria prática, Porto Alegre, v. 3, n. $1,2000$.

BAKHTIN, M. Estética da Criação Verbal. 3. ed. São Paulo: Martins Fontes, 2000. 
CANEVACCI, M. Fetichismos Visuais: corpos erópticos e metrópole comunicacional. São Paulo: Ateliê Editorial, 2008.

CRUZ, C. Metamorfoses de Kafka. São Paulo: Anablume/ FAPESP, 2007.

DUARTE, R. Teoria Crítica da Indústria Cultural. Belo Horizonte, UFMG, 2003.

DUARTE, N. (org). Crítica ao Fetichismo da Individualidade. Campinas: Autores Associados, 2004.

JENKINS, H. Cultura da Convergência. São Paulo: Aleph, 2008.

PARDO K., H. Geekonomía: um radar para producir em el postdigitalismo. Collecció Transmedia XXI. Publicacions i Edicions de La Universitat de Barcelona. Barcelona, 2010. e-book.

PIZZI, L.C.V; FUMES, N.F (orgs). Formação do Pesquisador em Educação: identidade, diversidade, inclusão e juventude. Maceió, EDUFAL. 2007.

PRENSKY, M. H. Sapiens Digital: From Digital Immigrants and Digital Natives

Digital

Wisdom.

Disponível

em:

http://innovateonline.info/pdf/vol5 issue3/H. Sapiens Digital-

From Digital Immigrants and Digital Natives to Digital Wisdom.pdf.

Acesso em: jul. 2010.

SANTAELLA, L.; NÖTH, W. Imagem, cognição, semiótica, mídia. São Paulo: lluminuras, 1998.

SAVIANI, D. Pedagogia no Brasil: história e teoria. Campinas: Autores Associados, 2008.

SETTON, M.da G.J. (org). A Cultura da Mídia na Escola: ensaios sobre cinema e educação. São Paulo: Annablume, USP, 2004. 